\title{
Insulin Treatment of Diabetes Mellitus
}

\author{
H. ST. GEORGE TUCKER, M.D.
}

Division of Endocrinology, Department of Medicine, Medical College of Virginia, Health Sciences Division of Virginia Commonwealth University, Richmond, Virginia

Dr. Harold Rifkin*, has previously set forth the reasons why we should try to keep the diabetic patient's blood sugar as near normal as possible. What are the generally accepted standards of good diabetic control?

Marble $^{1}$ considered control of the insulin-dependent diabetic good if the whole blood glucose before meals was not over $130 \mathrm{mg} \%$ (= serum glucose 150 $\mathrm{mg} \%$ ), the 24-hour urinary glucose did not exceed $5 \%$ of the carbohydrate intake, and there was no ketonuria; Oakley et $\mathrm{al}^{2}$ defined satisfactory control as blood glucose before meals of less than $150 \mathrm{mg} \%$ with no hypoglycemia; Lewis et $\mathrm{al}_{,}{ }^{3}$ in a recent paper dealing with pregnant diabetics, recommended fasting blood glucose below $100 \mathrm{mg} \%$ and blood glucose two hours after breakfast below $160 \mathrm{mg} \%$.

In some diabetics we can accomplish this type of control; in others we cannot. The maturity onset diabetic has some endogenous insulin under autoregulatory feedback control and, with a judicious diet or with the addition of a sulfonylurea drug or some exogenous insulin, near normal blood sugars can be achieved. However, in the juvenile or young adult onset diabetic, with little or no endogenous insulin, it is very difficult, even with complicated schedules of administration of insulin, to get blood sugars anywhere near normal without producing hypoglycemia.

A reasonable goal for every diabetic would be to maintain blood sugars as near normal as possible without producing hypoglycemia and without requiring a program so restrictive that it interferes with the quality of life.

* see preceding abstract.

Correspondence and reprint requests to Dr. H. St. George Tucker, Division of Endocrinology, Box 111, Medical College of Virginia, Richmond, Virginia 23298.
Figure 1, taken from a paper by Molnar et al, ${ }^{4}$ illustrates the daily variations in plasma insulin and blood glucose throughout a 24-hour period in a normal individual. Meals, snacks, and standard exercise periods are indicated. It is apparent that each feeding is accompanied by a sharp peak in insulin secretion which brings about disposal of ingested glucose and amino acids, and limits the blood sugar rise.

It is obvious that no one injection of intermediate-acting insulin can in any way duplicate the normal insulin pattern. At best an injection of $\mathrm{NPH}^{\circledR}$ or Lente ${ }^{(\sqrt{k})}$ Insulin given before breakfast will be absorbed for the most part over the next 8 to 12 hours when meals will be eaten, with some carry-over effect during the night. As diabeticians we hope to accomplish blood sugar levels that average somewhere near normal, but obviously the blood sugar will rise too high after meals and may fall too low before the next meal. Further leveling out may be accomplished by the addition of between-meal and bedtime snacks. We always insist on midafternoon and bedtime snacks in every patient on $\mathrm{NPH}^{\circledR}$ or Lente $\left.{ }^{(}\right)$Insulin.

Bressler and Galloway ${ }^{5}$ some years ago called attention to variations in the timing of effect of various insulins (Fig 2). Diabetics were divided into those showing a normal (B) response, a transient (A) response, or a delayed $(\mathrm{C})$ response to $\mathrm{NPH}^{\circledR}$ or Lente ${ }^{\circledR}$ Insulin. Those with a normal response could be moderately well regulated with a single morning injection of $\mathrm{NPH}^{(i)}$ or Lente ${ }^{(i)}$ Insulin. Those with a transient response might benefit from a second small dose of $\mathrm{NPH}^{(i)}$ or Lente ${ }^{(i)}$ Insulin before supper, and those with a delayed response might require the addition of regular insulin to the morning dose of $\mathrm{NPH}^{\circledR}$ or Lente $^{(\mathbb{B})}$ Insulin. The reasons for this variation in the timing of effect of the intermediate-acting insulins is not known. One possible factor delaying the action of 


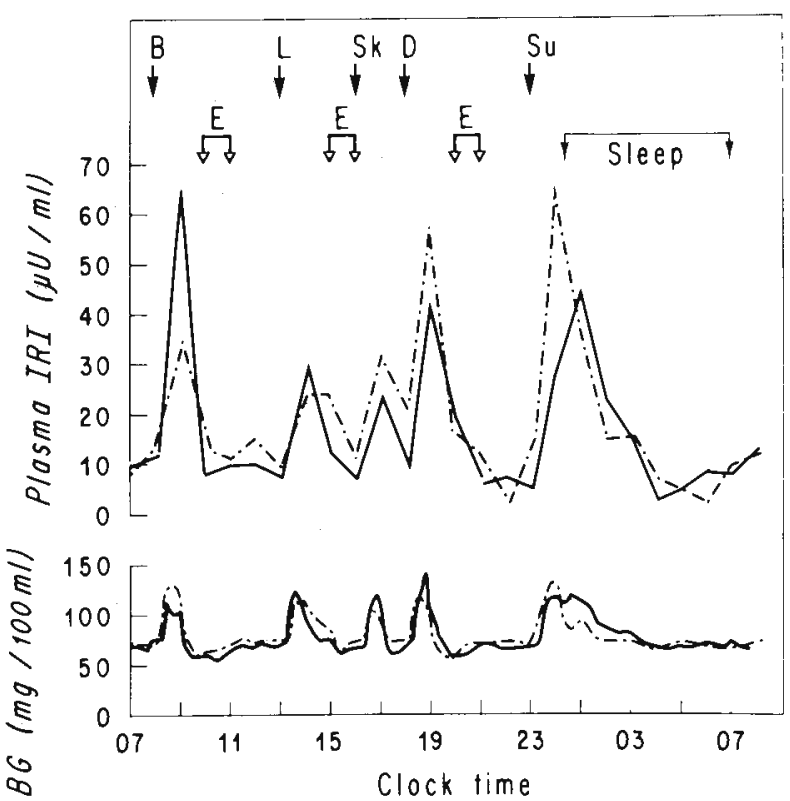

Fig 1-Meal-to-meal and day-to-day variations in blood glucose and immunoreactive insulin in a normal subject on two successive days (solid line represents first day; interrupted line represents second day). $\mathrm{B}=$ breakfast, $\mathrm{L}=$ lunch, $\mathrm{Sk}=$ snack, $\mathrm{D}=$ dinner, $\mathrm{Su}=$ supper, $\mathrm{E}=$ exercise, one hour of walking.

insulin is its binding to antibodies, with subsequent release, which prolongs the insulin effect.

Lukens, ${ }^{6}$ Forsham, ${ }^{7}$ and others pointed out some time ago that multiple injections of regular insulin before meals, perhaps accompanied by one or more injections of longer-acting insulin to control overnight blood sugar, would more closely resemble normal physiology and would be likely to give better control than a single injection of long- or intermediate-acting insulin. Indeed it is doubtful whether the medical profession did diabetic patients any favor when some years ago it abandoned multiple insulin injections in favor of the once-a-day injection of longer-acting preparations. Once the diabetic public became accustomed to the single morning injection it was difficult to persuade patients to go back to multiple injections and, by and large, doctors have seldom made the effort.

Recently there has been a renewal of interest in the use of multiple injections of regular insulin to accomplish more physiologic control, especially since reports from Paris by Job et $\mathrm{al}^{8}$ seem to indicate that such regimens in juvenile diabetics result in better control and in less progression of retinopathy. Also, especially good control in pregnant diabetics with multiple injections appears to result in lower infant mortality and morbidity, ${ }^{3}$ although better obstetrical techniques for monitoring the pregnancy and timing of delivery are equally important factors in the improved outcome in these patients. Thus a number of schedules of insulin administration have been proposed as illustrated in Table 1. There is good rationale for each of these programs in a given situation, although it is unlikely that any one type of program will be best for all patients.

Attempts have been made to define complicated dosage schedules even more rigidly. Lewis et $\mathrm{al}^{3}$ recommend the following formula for insulin administration for pregnant diabetics:

$$
\begin{aligned}
& \text { Morning NPH } \\
& \overline{\text { Morning reg. ins. }}=2: 1 \\
& \text { Evening } \mathrm{NPH}^{\left({ }^{*}\right.} \\
& \overline{\text { Evening reg. ins. }}=1: 1 \\
& \text { Morning total }=2 \times \text { evening total }
\end{aligned}
$$

I have tried this schedule with several pregnant diabetics with quite varied results. I think the reasoning is right, but it should be remembered that no two diabetic patients will respond in exactly the same

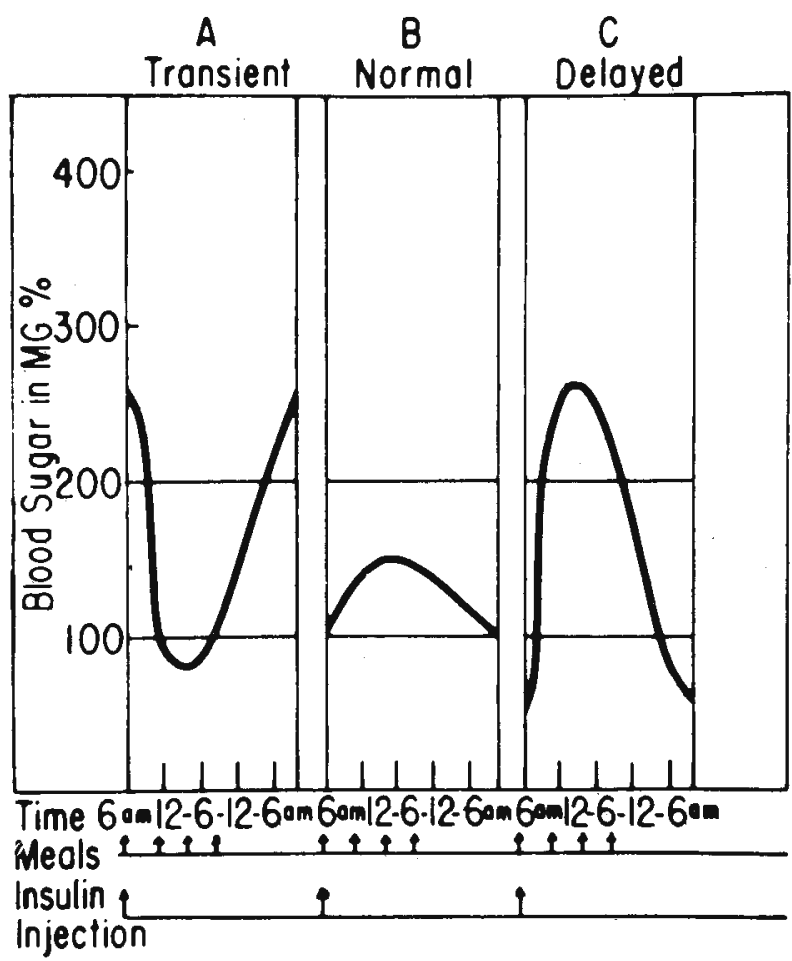

Fig 2-Blood sugar responses to a single daily dose of $\mathrm{NPH}^{\text {(x) }}$ Insulin. 
TABLE 1

Various Schedules for Insulin Administration

\begin{tabular}{|c|c|c|c|c|}
\hline Breakfast & Lunch & $\begin{array}{l}\text { Afternoon } \\
\text { Snack }\end{array}$ & Supper & $\begin{array}{c}\text { Bedtime } \\
\text { Snack }\end{array}$ \\
\hline \multicolumn{5}{|l|}{$\mathrm{N}$} \\
\hline \multicolumn{5}{|l|}{$\mathrm{R}+\mathrm{N}$} \\
\hline $\mathrm{N}$ & & & $\mathrm{N}$ & \\
\hline $\mathrm{R}$ & $\mathrm{R}$ & & $\mathrm{N}$ & \\
\hline $\mathrm{R}$ & $\mathrm{R}$ & & $R+N$ & \\
\hline $\mathrm{R}+\mathrm{N}$ & & & $\mathrm{R}+\mathrm{N}$ & \\
\hline
\end{tabular}

$\left(\mathrm{N}=\mathrm{NPH}^{\mathrm{k}}\right.$ or Lente ${ }^{\mathrm{k}}$ Insulin. $\mathrm{R}=$ regular or crystalline zinc insulin.)

way-there are just too many variables. Some of these are listed in Table 2.

How then should one approach insulin treatment in any given patient? Two basic principles are helpful: (1) analyze what kind of diabetic the patient is, and (2) keep the variables at a minimum.

The first principle means to try to form some idea of how much endogenous insulin the patient has from evaluation of the age of onset of the diabetes, his or her weight at onset, and the severity of symptoms at onset, especially weight loss. Onset of diabetes early in life, severe polyuria and polydipsia, and especially weight loss from uncontrolled diabetes, usually indicate total or near total insulin deficiency. If the patient has been on treatment, the diabetician should also consider the occurrence of ketoacidosis

TABLE 2

Variable Factors Limiting Good Blood Sugar Control with Exogenous lnsulin

1. Variations in food intake

2. Variations in exercise

3. Emotional factors and other stresses

4. Factors affecting the availability and effectiveness of administered insulin:

(a) variable absorption rates from injection site

(b) variable antibody titers and uncertain rates of release of insulin from antibodies

(c) variations in receptor binding sites and in their affinity for insulin

5. Variations in glucagon secretion

6. Hypoglycemia with rebaund hyperglycemia caused by counter-regulatory factors

7. Exogenous insulin is delivered into systemic circulation and not primarily into portal circulation and to the liver as is endogenously secreted insulin or frequent hypoglycemic reactions, both of which suggest that the patient has little or no endogenous insulin. If the patient has been controlled in the past on oral agents he or she must have had some endogenous insulin at that time.

The second principle, keeping the variables at a minimum, means trying to get the patient to maintain reasonably constant eating habits and exercise patterns as well as simplifying the insulin schedule until the need for multiple doses becomes apparent. In general, begin with a single dose of $\mathrm{NPH}^{\circledR}$ or Lente ${ }^{\circledR}$ Insulin every morning, perhaps 20 units if the patient has never before taken insulin. Instruct the patient in a proper diet, which probably should include both afternoon and evening snacks, for his or her weight and activity. The patient may continue working but should test his or her urine four times daily, before meals and at bedtime. If the patient continues to spill sugar, increase the insulin by 5 units every four or five days until some negative urine tests are obtained. Check the blood sugar at the time of the negative urine test, and if this is still high, continue to increase the insulin until the blood sugar is in the desired range. If any hypoglycemic reactions occur, the insulin dose should be reduced. As the patient approaches control the urine tests should be determined from second voidings whenever the first voiding contains sugar.

Many diabetics will come under satisfactory control with a single morning dose of $\mathrm{NPH}^{(*)}$ or Lente Insulin. If glycosuria or hyperglycemia persists before breakfast, with negative tests in the afternoon, the patient may be classified as a transient responder, and a second small dose of $\mathrm{NPH}^{(i)}$ or Lente $^{k 1}$ Insulin should be added before supper. If the morning test is repeatedly negative but glycosuria persists before lunch, the patient may be a delayed responder, and regular insulin can be added to the morning $\mathrm{NPH}^{(\mathrm{k})}$.

If the desired degree of control is not achieved by these measures, both regular and $\mathrm{NPH}^{\circledR}$ Insulin may be given twice daily. In general the indications for administration of such multiple doses would follow a schedule such as in Table 3, as suggested by Oakley et al. $^{2}$

In a highly reliable and highly motivated patient, such as a pregnant diabetic, this type of program may succeed; or a highly obsessive patient may religiously seek perfect control. Unfortunately most patients are not so reliable, and the obsessive ones usually end up making themselves hypoglycemic. 
TABLE 3

Management of the Severe Diabetic with Twice Daily Injections of Regular and NPH ${ }^{\mathbb{B}}$ Insulin

\begin{tabular}{|c|c|c|}
\hline Insulin & $\begin{array}{c}\text { Period of } \\
\text { Maximum Action }\end{array}$ & $\begin{array}{l}\text { Timing of urine or } \\
\text { blood sugar for } \\
\text { dose adjustment }\end{array}$ \\
\hline Morning RI & Breakfast to lunch & Pre-lunch \\
\hline Morning $\mathrm{NPH}^{\text {w }}$ & Lunch to supper & Pre-supper \\
\hline Evęning RI & Supper to midnight & Bedtime \\
\hline Evening NPH ${ }^{(a)}$ & Midnight to breakfast & Pre-breakfast \\
\hline
\end{tabular}

What do you do with the patient who never shows any consistent pattern? You look for such variables as food intake, exercise, emotional upsets, and other factors. Hypoglycemia, recognized or unrecognized, is the cause of much brittleness. For every recognized hypoglycemic reaction, the brittle juvenile diabetic has ten other occasions when the blood sugar is quite low without his knowledge, and each may be followed by rebound hyperglycemia. You must learn to recognize this pattern and to reduce insulin accordingly. Tables 4 and 5 illustrate two such patients.

Table 4 is a record of the urine sugars on a 23year-old dental student with diabetes of two years' duration, during which he took 12 units of Semilente ${ }^{(i)}$ and 20 units of Lente ${ }^{\circledR}$ Insulin daily. He was on a 2500-calorie diet including three main meals and midafternoon and bedtime snacks. He was extremely conscientious and liked to keep all his urine tests negative. To keep himself in physical trim he ran two

TABLE 4

Insulin Dosage and Urine Tests Showing Glycosuria Following Asymptomatic and Unrecognized Hypoglycemia

\begin{tabular}{|c|c|c|c|c|c|}
\hline \multicolumn{3}{|c|}{ J.S. (Male, 23) } & \multicolumn{3}{|c|}{ Urine sugars } \\
\hline \multicolumn{2}{|c|}{ Insulin } & 7 & 11 & 4 & 9 \\
\hline \multicolumn{2}{|c|}{$12 \mathrm{SL} \pm 20 \mathrm{~L}$} & $\mathrm{~N}$ & $\mathbf{N}$ & $N$ & $\mathrm{~N}$ \\
\hline$"$ & $"$ & $N$ & $\mathrm{~N}$ & $\mathrm{~N}$ & $N^{*}$ \\
\hline$"$ & $"$ & $4+$ & $4+$ & $\mathrm{N}$ & $N$ \\
\hline$"$ & $"$ & $\mathrm{~N}$ & $\mathbf{N}$ & $\mathrm{N}$ & $\mathrm{N}^{*}$ \\
\hline$"$ & $"$ & $2+$ & $3+$ & $\mathrm{N}$ & $\mathrm{N}$ \\
\hline$"$ & $"$ & $\mathbf{N}$ & $3+$ & $\mathrm{N}$ & $N^{*}$ \\
\hline$"$ & $"$ & $3+$ & $\mathrm{N}$ & $\mathbf{N}$ & $4+$ \\
\hline$"$ & $"$ & $4+$ & $1+$ & $\mathrm{N}$ & $N$ \\
\hline$"$ & $"$ & $\mathbf{N}$ & $\mathbf{N}$ & $\mathrm{N}$ & $N$ \\
\hline
\end{tabular}

* Ran approximately 2 miles

$\left(\mathrm{SL}=\right.$ Semilente ${ }^{\text {*k: }}$ Insulin. $\mathrm{L}=$ Lente $^{(i)}$ Insulin. $)$ miles several times a week, and because of his busy schedule chose the late evening as the time for his exercise. He was not conscious of any hypoglycemic reactions, but he invariably showed unexpected sugar in his urine on the mornings after running; when he had not run the night before, his tests were almost all negative. It became apparent that the additional exercise was causing undetected hypoglycemia during the night, followed by rebound hyperglycemia and glycosuria the next day, the so-called Somogyi effect caused by the secretion of epinephrine, glucagon, cortisol, and growth hormone in response to hypoglycemia. The situation was corrected by insisting that he take sizable extra feedings just before and just after his nocturnal exercise periods; this prevented the hypoglycemia and its consequent rebound.

The Somogyi rebound hyperglycemia following hypoglycemia is most often seen in the brittle juvenile diabetic, but can be observed in any insulin-dependent diabetic. Table 5 shows the record of urine tests on a 72-year-old diabetic taking 32 units of $\mathrm{NPH}^{(1)}$ Insulin daily. He also was very conscientious and very careful about his diet. After a series of days with all negative urine tests, he showed unexpected $4+$ sugar at noon on Aug 29 and Aug 30, with sugar

TABLE 5

Insulin Dosage and Urine Tests in an Older Diabetic Showing Glycosuria, Probably Representing Rebound After Unrecognized Hypoglycemia

\begin{tabular}{|c|c|c|c|c|c|}
\hline \multicolumn{6}{|c|}{ J.V.C. (Male, 72) } \\
\hline & $\mathrm{NPH}^{(\mathrm{k})}$ & 7 & 12 & 5 & 9 \\
\hline $8 / 27$ & 32 & $\mathrm{~N}$ & $N$ & $\mathrm{~N}$ & $4+$ \\
\hline $8 / 28$ & $"$ & $\mathrm{~N}$ & $\mathbf{N}$ & $\mathrm{N}$ & $\mathrm{N}$ \\
\hline $8 / 29$ & $"$ & $\mathbf{N}$ & $4+$ & $1+$ & $3+$ \\
\hline $8 / 30$ & $"$ & $\mathbf{N}$ & $4+$ & $4+$ & $4+$ \\
\hline $8 / 31$ & 30 & $\mathrm{~N}$ & $\mathrm{~N}$ & $\mathrm{~N}$ & $\mathbf{N}$ \\
\hline $9 / 1$ & $"$ & $\mathbf{N}$ & $\operatorname{tr}$ & $\operatorname{tr}$ & $\mathrm{N}$ \\
\hline $9 / 2$ & $"$ & $\mathrm{~N}$ & $\mathrm{~N}$ & $3+$ & $3+$ \\
\hline $9 / 3$ & $"$ & $\operatorname{tr}$ & $\operatorname{tr}$ & $N$ & $4+$ \\
\hline $9 / 4$ & $"$ & $\mathbf{N}$ & $\mathrm{N}$ & $N$ & $\mathbf{N}$ \\
\hline $9 / 5$ & $"$ & $\mathbf{N}$ & $N$ & $\mathbf{N}$ & $N$ \\
\hline $9 / 6$ & $"$ & $N$ & $\mathbf{N}$ & $\mathbf{N}$ & $N$ \\
\hline $9 / 7$ & $"$ & $\mathrm{~N}$ & $\mathrm{~N}$ & $\mathbf{N}$ & $\mathbf{N}$ \\
\hline $9 / 8$ & $"$ & $\mathrm{~N}$ & $\operatorname{tr}$ & $\operatorname{tr}$ & $4+$ \\
\hline $9 / 9$ & $"$ & $\mathrm{~N}$ & $2+$ & $\mathrm{N}$ & $3+$ \\
\hline $9 / 10$ & $"$ & $3+$ & $3+$ & $\mathbf{N}$ & $4+$ \\
\hline $9 / 11$ & $"$ & $\mathbf{N}$ & $2+$ & $4+$ & $4+$ \\
\hline $9 / 12$ & $"$ & $3+$ & $\mathrm{tr}$ & $\mathrm{N}$ & $N$ \\
\hline $9 / 13$ & $"$ & $1+$ & $3+$ & $\mathrm{N}$ & $\mathbf{N}$ \\
\hline $9 / 14$ & $"$ & $\mathrm{~N}$ & $N$ & $\mathrm{~N}$ & $\mathbf{N}$ \\
\hline
\end{tabular}


persisting during the rest of the day. Questioning revealed no dietary indiscretions, no variation in exercise, and no emotional upsets or other stresses to account for the glycosuria. Although he was unaware of any hypoglycemic symptoms, it seemed inconceivable that the dose of insulin which had kept his tests all negative over the previous days could be so inadequate on these days. I suspected unrecognized hypoglycemia and reduced his $\mathrm{NPH}^{\circledR}$ Insulin to 30 units. The urine tests improved and remained all negative until Sep 8 when he again began to show sugar in the evening test. Not shown in Table 5 is the fact that his $\mathbf{N P H}^{\circledast}$ Insulin was lowered again to 28 units and later to 26 units with improvement each time and, finally, all negative urine tests. He remained on 26 units of $\mathrm{NPH}^{\circledR}$ for several months, then began to spill sugar in all specimens; the $\mathrm{NPH}^{\circledR}$ Insulin dose has been gradually raised again to 30 units with good control. The reason for these swings in insulin requirement over periods of several months is unknown. Some patients go through cycles when their insulin requirement goes up or down for no apparent reason; these may be over months or over shorter periods. All we can do is to try to keep pace through adjustments in insulin dose.

When the patient alternates between good days and bad days, with lots of sugar or no sugar, suspect hypoglycemia with rebound. In any event you should adjust the patient's insulin dose to his or her better days and not try to give more for the bad days or you will surely produce hypoglycemia.

The bane of the diabetician's existence is the obese patient on insulin. If these patients could have been made to reduce in the beginning, many of them would not have needed insulin. Once on insulin, lipolysis is inhibited, weight reduction becomes even more difficult, and these patients tend to gain more weight which increases insulin resistance, creating a vicious circle of upward spiraling weight and insulin dosage. In this instance it may be better to cut back the insulin dosage and let the patient spill sugar until somehow he or she can be persuaded to really limit food intake. There is no satisfactory answer to this problem unless the patient loses weight.
In summary, I believe in aiming for the best possible control for each patient through an empirical approach which seeks to arrive at the best schedule for the individual patient. We want especially tight control for the pregnant diabetic, and for this patient it is likely that multiple insulin injections are needed. If further experience confirms the benefits of multiple injections for juvenile patients, this type of treatment may also be indicated for these patients.

Figure 1 is reproduced with permission from Mayo Clinic Proceedings (47:709-719, 1972).

Figure 2 is reproduced with permission from Medical Clinics of North America (55:861-868, 1971).

Table 3 is reproduced with permission from Diabetes $(15: 219-222,1966)$.

\section{REFERENCES}

1. Marble A: Therapy: criteria of control, in Danowski TS (ed): Diabetes Mellitus: Diagnosis and Treatment. New York, American Diabetes Association, 1964, vol 1, pp 69-71.

2. Oakley W, Hir.t. D, Oakley N: Combined use of regular and crystalline protamine (NPH) insulins in the treatment of severe diabetes. Diabetes 15:219-222, 1966.

3. Lewis SB, Murray WK, Wallin JD, et al: Improved glucose control in nonhospitalized pregnant diabetic patients. Obstet G.necol 48:260-267, 1976.

4. Molnar GD, Taylor WF, Langworthy al: Plasma immunoreactive insulin patterns in insulin-treated diabetics. Studies during continuous blood glucose monitoring. Mayo Clin Proc 47:709-719, 1972.

5. Bressler R, Galloway, JA: Insulin treatment of diabetes mellitus. Med Clin North Am, 55:861-876, 1971.

6. LUKENS FDW: The rediscovery of regular insulin. $N$ Engl $J$ Med 272:130-137, 1965.

7. Forsham $\mathrm{PH}$ : Insulin twice a day suggested for control. JAMA 202:26, 1967.

8. Job D, Eschewege E, Guyot-Argenton C, et al: Effect of multiple daily insulin injections on the course of diabetic retinopathy. Diabetes 25:463-469, 1976. 